Europe's Journal of Psychology 3/2009, pp. 3-8

www.ejop.org

\title{
Research and practice in organizational sciences Interview with Frederick P. Morgeson
}

By Dan Ispas and Alexandra llie

EJOP Senior Editors

University of South Florida

Studied under various names such as industrial-organizational psychology, organizational behavior, human resources management etc., organizational sciences share a focus on both research and practice. However, most of the actors in the field chose one over the other. For this issue's interview, we talked to Dr. Fred Morgeson a prolific researcher who successfully combined science and practice in his work.

Frederick P. Morgeson (www.morgeson.com) is a Professor of Management and Valade Research Scholar at the Eli Broad College of Business at Michigan State University. He received his Ph.D. in Industrial and Organizational Psychology from Purdue University.

Dr. Morgeson teaches and does research in Human Resource Management and Organizational Behavior. His research has focused on four distinct areas. First, he has a continuing interest in leadership, particularly with respect to the role of leadership in self-managing teams and the nature of the relationship between leaders and followers. Second, Dr. Morgeson has examined fundamental questions about the nature of work, which includes how work is structured and how people perceive their work. These issues have been explored in a series of studies in the job analysis, work design, and work teams areas. Third, he has studied the effectiveness and consequences of different selection techniques. Fourth, Dr. Morgeson has explored issues of theory development and sought to produce integrative research in the substantive research areas noted above.

This research has been published (or is forthcoming) in Academy of Management Journal, Academy of Management Review, Academy of Management Learning and Education, American Psychologist, Consulting Psychology Journal: Practice and Research, Human Performance, Human Resource Management, International Journal of Selection and Assessment, Journal of Applied 
Psychology, Journal of Business and Psychology, Journal of International Business Studies, Journal of Management, Journal of Organizational Behavior, Journal of Quality Management, Leadership Quarterly, Organizational Behavior and Human Decision Processes, and Personnel Psychology. In addition, he has co-authored the leading job analysis book (Job Analysis: Methods, Research, and Applications for Human Resource Management), authored or co-authored numerous book chapters, and presented over 75 papers at professional meetings. Finally, Dr. Morgeson is the Associate Editor of Personnel Psychology, is on the Editorial Committee for the Annual Review of Psychology, is a member of the Academy of Management's HR Division Executive Committee. Prior to his academic career, Dr. Morgeson was a manager at a recording studio in the Detroit area. In addition, he has been involved in variety of consulting and applied research projects for a number of organizations in the areas of job analysis, work design, recruiting, personnel selection, leadership development, compensation, and organizational assessment.

EJOP: Numerous papers have been written about the "scientist-practitioner" gap in organizational research. You have successfully combined science and practice in your work. What can be done to narrow this gap?

Frederick Morgeson: Although there is often quite a bit of collective hand-wringing about the scientist-practitioner gap in our field, it is important to recognize that there are many practitioners who take a fairly sophisticated scientific or research-based approach in their work. Similarly, quite a few research oriented scientists find it a high honor to be able to work on problems that organizations find relevant. Thus, it seems that the key issue is how we can encourage more practitioners and scientists to work in the same manner.

I think one of the things that contribute to this gap is that scientists often study things that organizations don't care about. Thus, one way to help close the gap would be for academics to go out into the field and work with organizations, either in a consulting/advisory capacity or through applied research projects. By interacting with organizational members, academics can gain a better understanding of the range of issues organizations face. This will help academics identify (and hopefully study) pressing organizational problems, thereby closing the scientist-practitioner gap. Another tool that could help address this gap is to create additional forums for publishing research that is more accessible (and relevant) to practitioners. It seems that as the organizational sciences have evolved, we have developed an increasingly technical and formulaic form of academic writing. Thus, most research published in our top journals typically must forward a set of carefully developed 
hypotheses that draw from various theories but also somehow extend or contribute to those same theories. Yet, sometimes there are compelling practical problems that research can address and the typical journal article is ill-suited to address. Although there are some places where such research can be published (e.g., the ScientistPractitioner Forum in Personnel Psychology), there are few other top-tier outlets where such research can be presented. This would seem to further separate science from practice. Finally, as a field I think we should insist that practice be based on sound science. Thus, I think we should actively oppose those that seek simplistic solutions to complex problems, the proliferation of buzzwords or fads that seem to favor marketing over science, and the development of proprietary tools (e.g., instruments, measures) that are not freely available to the broader scientific community.

Having said all of this, however, it is important to recognize that there is a role for research that does not address any immediate or obvious practical problems. Thus, the challenge for the field is to ensure a balance of basic and applied research.

EJOP: It is generally acknowledged that it is quite difficult to gain access to organizations to collect data. What are some of the strategies researchers could use to facilitate their access to organizational data?

Frederick Morgeson: Probably the biggest aid to gaining access to organizational data is to study issues organizations find interesting. Organizations are sometimes willing to help researchers answer the questions the researcher is interested in, but more often than not they are mainly interested in better understanding something that they are struggling with. My own research interests tend toward applied issues and this aligns well with studying the kinds of organizational problems I noted earlier. For example, some of my research has involved understanding the role of formal leaders in self-managed teams. When I started this work (in the mid-1990's), many organizations were still struggling to understand the role of these leaders. As such, I found that many organizations were interested in partnering with me to help me conduct the research. Of course, simply studying something they find interesting often isn't enough. You also have to articulate and provide something of value to the organization. That could be a report, feedback to research participants, or some sort of training initiative. Whatever it is, however, you have to clearly demonstrate the value of your research. This is certainly aided by focusing on topics of interest to the organization.

EJOP: Top-tier academic journals have become more and more reluctant to publish cross-sectional self-report studies. What are your views on this trend? Are there any possible negative consequences? 
Frederick Morgeson: We have long known that there are many weaknesses associated with single-source, single-method, single-time period data collection efforts (Campbell \& Fiske, 1959). As such, it is surprising that scholars would utilize such research designs given what is known about the problem and the admonition against conducting such research (Campbell, 1982). The weakness of such study designs are so well-known and understood that this is identified by virtually every reviewer and editor of our major journals as a "fatal flaw." I doubt this will change at any point in the near future, and this isn't such a bad thing. As science progresses rigor typically increases. This is good.

EJOP: Some say there is a striking difference between current research from top-tier academic journals and research published in the same journals in the 80s or early 90s: the number of pages dedicated to theoretical development of the hypotheses has increased dramatically. At the same time, top-tier journals from other fields such as the natural sciences are publishing shorter papers with minimal introductions and a focus on the findings. Is there a danger of over-emphasizing theory? Should we adopt the natural sciences model?

Frederick Morgeson: As I noted earlier, I think one of the reasons for the scientistpractitioner gap is the evolution of our field to one that is much more dependent on theory development and the theoretical contribution of a manuscript. This is probably a good trend, but perhaps one of the costs of this trend is that we are going to miss some particularly interesting and novel empirical findings that cannot be well-anchored in existing theory. Perhaps we should be more willing to publish papers that primarily make an empirical (rather than a theoretical) contribution. Of course, this would require a fairly substantive empirical contribution, and it is not clear that many (primarily) empirical studies would actually meet this standard. Yet, I suspect we should seek more of a balance between theory and empiricism, rather than rather a potential (over) emphasis on theory.

EJOP: You have published numerous papers in top tier academic journals. What advice do you have for novice researchers?

Frederick Morgeson: There are many outstanding places to get advice and learn about the publishing process (e.g., Cummings \& Frost, 1995), so I'm afraid that what I'm going to say will not be particularly ground-breaking. Nonetheless, I think there are a handful of things that can help you a successful scholar, assuming that you define "success" as publishing in top-tier academic journals. This isn't always an appropriate definition of success for everyone, but that's a different question entirely. 
First, it is essential that your interest in research and the topic you are studying come from your own curiosity and engagement in answering a particular question rather than from some sort of extrinsic reward (e.g., getting a "pub"). Although I suppose there are many extrinsic rewards associated with publishing, such rewards are often distal, uncertain, and ultimately not sustaining for life as a scholar. Intrinsic motivation, however, will help you persevere when you encounter difficulty and makes life so much more enjoyable. So, I guess my advice here would be to simply do what you love to do (in terms of topic and research more generally). If you find that you really don't love research, perhaps you should seek an alternative career path.

Second, you need to have a certain amount of what one might call technical skill. This is the "blocking and tackling" of science. Can you design a study? What kinds of statistical techniques do you know? Can you write clearly? Without these skills you will have a tough time as a scholar. Yet, such technical skills are necessary but not sufficient. So, third, you also need to have good ideas. You can think of these as conceptual skills, and they revolve around understating a literature, being able to identify interesting and important research questions, and being able to tell a compelling story with your research. This seems to be a rarer commodity than technical skills. One way to develop one's conceptual skill (and because it's a skill it can be developed) is to gain a mastery of the literature and the topic you're studying. If you know everything there is to know about the topic, you will have a much better idea about how to frame your own research (and what constitutes "enough" of a contribution in a given paper).

Fourth, being resilient and persistent turns out to be pretty important. These traits are important because all research involves numerous challenges that you must overcome. For example, you often get receive negative feedback as you pursue your research. This can come from a dissertation committee, the review process, or your own self-editing. Do you view this kind of feedback as a (negative) indicator of your own competence and use it as an excuse to give up? Or do you view it as valuable feedback that can stimulate adaptation and learning? In addition, in virtually all research you will reach a point where you're not sure how to proceed. It may be a seemingly intractable conceptual problem, difficulty in securing a research site, or uncertainty about how to respond to reviewers. Every scholar, no matter how successful, routinely encounters such difficulties. What differentiates successful from unsuccessful scholars is their response (hint: they don't give up).

Fifth, it goes without saying that you need to work hard. Conducting research and seeing it though to publication takes a lot of time and effort. Most highly productive 
scholars work pretty hard at it. This really isn't all that different from any other domain or career field. To be successful requires quite a bit of work.

EJOP: What can international scholars do to increase their chances of publications in top-tier English journals?

Frederick Morgeson: What I find so wonderful about our field (especially top-tier journals) is that it is a meritocracy: You are judged by the quality of your work, not who you are or where you come from. For example, there are well-known criteria against which journal submissions are judged and reviewer judgments are done in the absence of knowledge of the author's identity. Thus, the advice I would give to any scholar, regardless of his or her location, would be to learn about the journal you seek to publish in, understand what they are looking for in terms of theory and methods, and hone your skills so you can write manuscripts that will fit with that journal. One way to do this is to extensively read articles published in that particular journal. This will better enable you to understand the mission and focus of that journal and likely increase your chance of success.

Most top-tier journals, however, are published in the English language. This obviously poses a major challenge for non-native English-speaking scholars. So, enhancing English writing skills is a key task. There are numerous writing guides that can help. One of my favorites is Strunk and White's Elements of Style. It offers all sorts of specific tips and techniques for writing clearly. Another strategy is to develop a peer network with native English-speaking scholars who can read drafts of manuscripts and help refine the writing. A final strategy is what I noted earlier. Read the journal so you can get a sense of its tone and content. See how authors structure arguments and transition between topics and sections. Understand how one builds a compelling story throughout the manuscript. Be very deliberate at analyzing the components of the articles, particularly about how they are structured and developed. Doing these things will surely improve your writing skills.

\section{References}

Campbell, J. P. (1982). Editorial: Some remarks from the outgoing editor. Journal of Applied Psychology, 67, 691-700.

Campbell, D. T. \& Fiske, D. W. (1959). Convergent and discriminant validation by the multitrait-multimethod matrix. Psychological Bulletin, 56, 81-105.

Cummings, L. L., \& Frost, P. J. (Eds.) (1995). Publishing in the organizational sciences (2 ${ }^{\text {nd }}$ ed.). Thousand Oaks, CA: Sage. 